\title{
Development and Validation of UV-Spectrophotometric method for the Estimation of Curcumin in Standardised Polyherbal Formulations
}

\author{
Ashwinder Singh ${ }^{1}$ and Vasudeva Rao Avupati ${ }^{2 *}$ \\ 'Pharmaceutical Chemistry Division, Faculty of Pharmacy, Asia Metropolitan University, G-8 Jalan Kemacahaya 11, Taman Kemacahaya, 43200 Cheras, Selangor, MALAYSIA. \\ 2Pharmaceutical Chemistry Division, School of Pharmacy, International Medical University, 126, Jn Jalil Perkasa 19, Bukit Jalil, 57000 Bukit Jalil, Wilayah Persekutuan, \\ Kuala Lumpur, MALAYSIA.
}

\begin{abstract}
Objective: We aimed to develop and validate a simple UV-spectrophotometric method relates to the estimation of curcumin in standardised polyherbal formulations. Methods: Pure curcumin was received as generous gift sample from Andhra University, India, all solvents and reagents of analytical reagent (AR) grade were procured from local suppliers and readily used for the method development. The method validation parameters were evaluated as per International Conference on Harmonization (ICH) guidelines. Further, this method was applied for the assay of curcumin in marketed product Live-well ${ }^{\mathrm{TM}}$, CUMIN (standardised turmeric extract (STE) fortified with standardised black pepper (SBE) extract) capsules using UV-spectrophotometric method. Results and Discussion: It was confirmed from the results of method validation characteristics such as specificity, linearity, range, precision, accuracy, and robustness were keeping within the limits of acceptance criteria defined under ICH guidelines, $76.0560 \%$ of curcumin was estimated to be present in each Live-well ${ }^{\mathrm{TM}}$, CUMIN capsule containing a minimum $95 \%$ of the total curcuminoids (label claimed).
\end{abstract}

Conclusion: In summary, our method was found to be reliable in detecting the unknown percentage of curcumin in Live-wellTM, CUMIN capsule formulation. Also, the method was proved to be specific, linear, precise, accurate and robust to use for routine analysis of polyherbal formulations containing curcumin as their principal component in the extracts.

Key words: UV-spectrophotometric method, Curcumin, ICH Guidelines, Live-well ${ }^{\mathrm{TM}}$, CUMIN

\section{Correspondence :}

Vasudeva Rao Avupati, Pharmaceutical Chemistry Division, School of Pharmacy International, Medical University, 126, Jn Jalil, Perkasa 19 Bukit Jalil, 57000 Bukit Jalil, Wilayah Persekutuan Kuala Lumpur, MALAYSIA.

Phone: +60 167567763

Email: vasudevaraoavupati@gmail.com

DOI: 10.5530/jyp.2017.9.96

\section{INTRODUCTION}

In the post genomic era, World Health Organization (WHO) estimated about $80 \%$ of the world population uses herbs and other traditional medicines for their primary health care needs. ${ }^{1}$ Tremendous raise in the use of herbal medicine is leading to a fast-growing market of polyherbal formulations worldwide. ${ }^{2}$ Whereas, according to WHO guidelines, standardization of herbal products is essential in order to assess the quality, clinical safety and efficacy before releasing into the market. ${ }^{3}$ Turmeric (Curcuma longa Linn.) is a perennial herb belonging to the family Zingiberaceae also called curcumin. ${ }^{4}$ The yellow color of turmeric is mainly due to the presence of polyphenolic curcuminoids. ${ }^{5}$ In commercially marketed curcumin (turmeric extracts), curcumin, available in a mixture of three curcuminoids, usually contains $77 \%$ pure curcumin, $17 \%$ demethoxycurcumin and $3 \%$ bisdemethoxycurcumin. ${ }^{6}$ It has been reported that different species of Curcuma have different percentages of these individual curcuminoids. ${ }^{7}$ Among the curcuminoids, curcumin has been attained significant attention due to its bioactive potential. ${ }^{8}$ Numerous clinical trials over the past two decades have addressed the safety, and efficacy of this nutraceutical against multiple diseases including cancer, diabetes, acquired immunodeficiency syndrome (AIDS) etc. ${ }^{9}$ Acute toxicity studies have indicated the safety of curcumin at doses as high as $12 \mathrm{~g}$ /day over 3 months. $^{10}$ In complementary and alternative medicine therapies, curcumin has significant role either alone or in combination with other herbs. ${ }^{11}$ A variety of polyherbal formulations of turmeric extracts have been marketed commercially in which the percentage of curcumin is vital to ensure physiological benefits. Conversely, several marketed polyherbal formulations are available without labeled claim on relative percentage composition of individual curcuminoids. ${ }^{12}$ Several methods were reported for the estimation of curcumin in different pharmaceutical and herbal formulations by using UV, ${ }^{13}$ HPLC, ${ }^{14}$ UPLC, ${ }^{15}$ HPTLC, ${ }^{16}$ FT-IR ${ }^{17}$ and others hyphenated methods. ${ }^{18,19}$ However, these techniques are not suitable for analyzing compounds in combinations of polyherbal formulations like Ayurvedic or Chinese medicinal products, since they contain more than one herb. While UV-spectrophotometric methods are more suitable for this objective, studies on dedicated UV-spectrophotometric methods to quantify the curcumin in polyherbal formulations are very limited. ${ }^{20}$ Therefore, in the present study, a simple UV method was developed and validated according to international conference harmonization (ICH) guidelines for the quantitative estimation of curcumin in polyherbal formulations. ${ }^{21}$ The method has also been tested by using market available Live-well ${ }^{\mathrm{Ts}}$, CUMIN capsules. Literature survey also revealed that, to date, no UV method has been proposed using ethyl acetate as solvent for the assay of curcumin in polyherbal formulations.

\section{MATERIALS AND METHODS}

\section{Instruments}

Jasco double beam UV-Vis spectrophotometer (Model V-630) with $1.5 \mathrm{~nm}$ spectral bandwidth using $10 \mathrm{~mm}$ matched quartz cuvettes. Data acquisition was performed by using spectra manager software version 2.0 . Secom am single beam UV-Vis spectrophotometer (Model: XTD 6) with 
$2 \mathrm{~nm}$ spectral band width using $10 \mathrm{~mm}$ matched quartz cuvettes. All weights were taken on electronic analytical balance (Mettler Toledo ${ }^{\mathrm{Tx}}$, USA).

\section{Chemicals}

Pure curcumin was obtained as generous gift sample from Pharmaceutical Chemistry Research Laboratories, AU College of Pharmaceutical Sciences, Andhra University, Visakhapatnam, India. The capsule polyherbal formulation (Live-well ${ }^{\mathrm{mw}}$, CUMIN, PC: QG86, Batch No. 15N16, Mfg. Date. 05/15, Exp. Date 04/18) containing $400 \mathrm{mg}$ of Turmeric Standardised Extract (TSE) fortified with $2.5 \mathrm{mg}$ of Black pepper standardised extract (BSE) was procured from local retail pharmacy, Caring Pharmacy Sdn Bhd (CST) (296901-H), Jalan Cheras, Kuala Lumpur, Malaysia. Analytical grade ethyl acetate and all other chemicals were purchased from NEXBIO Sdn Bhd (1059366-H), Petaling Jaya, Selangor, Malaysia.

\section{Preparation of standard solutions}

Standard stock solution contain $100 \mu \mathrm{g} / \mathrm{mL}$ was prepared, $10 \mathrm{mg}$ of curcumin was accurately weighed and transferred into $100 \mathrm{~mL}$ volumetric flask and made up to the mark with ethyl acetate, standard solutions were prepared in the concentration range of $1-5 \mu \mathrm{g} / \mathrm{mL}$ by further dilution with ethyl acetate.

\section{Determination of wavelength of maximum absorbance $\left(\lambda_{\max }\right)$ of curcumin}

Wavelength of maximum absorption $\left(\lambda_{\text {max }}\right)$ was determined by scanning $10 \mu \mathrm{g} / \mathrm{mL}$ solution of curcumin using UV-visible double bean spectrophotometer from 400-600 nm using ethyl acetate as blank.

\section{Preparation of standard calibration curve}

The absorbances of the standard solutions in ethyl acetate at $1-5 \mu \mathrm{g} / \mathrm{mL}$ range was measured at $418 \mathrm{~nm}$. Standard calibration curve was prepared by plotting average $(n=3)$ maximum absorbance $\left(\lambda_{\max }\right)$ versus concentration. Linearity was studied using a regression equation.

\section{Method validation}

The method was validated according to ICH Q2(R1) guidelines for validation of analytical procedures. Typical validation characteristics such as specificity, linearity, range, precision, accuracy and robustness were considered for evaluation. These measurements regarded as the most important for the validation of assay type analytical procedure.

\section{Specificity}

Specificity was confirmed by UV-spectrophotometric scanning of each curcumin standard solution (1-5 $\mu \mathrm{g} / \mathrm{mL})$ in the range of $400-600 \mathrm{~nm}$ against ethyl acetate as blank.

\section{Linearity}

The linearity was determined by analyzing absorbance of the curcumin standard concentrations $(1-5 \mu \mathrm{g} / \mathrm{mL})$ at $418 \mathrm{~nm}$ against ethyl acetate as blank. The calibration curve was plotted using concentration against absorbance. A regression equation and correlation coefficient were determined for curcumin standard concentrations $(1-5 \mu \mathrm{g} / \mathrm{mL})$.

\section{Range}

The data obtained from the linearity and accuracy studies was used to assess the range of the method.

\section{Precision}

Precision was evaluated by using repeatability and intermediate precision. Repeatability was analyzed using curcumin $(1 \mu \mathrm{g} / \mathrm{mL})$ for six times in the same day (intra-day). The intermediate precision was analyzed using three curcumin concentrations $(1,3$ and $5 \mu \mathrm{g} / \mathrm{mL})$ for three times on three consecutive days (inter-day).

\section{Accuracy}

Accuracy was established by percentage recovery of known added concentrations of curcumin standard $(1,2$ and $3 \mu \mathrm{g} / \mathrm{mL})$ to the preanalyzed sample solutions $(2 \mu \mathrm{g} / \mathrm{mL})$. The method was repeated for three times for each concentration.

$$
\% \text { Recovery }=\left[\mathrm{C}_{\mathrm{t}} / \mathrm{C}_{\mathrm{a}}\right] \mathrm{x} 100
$$

Where

$\mathrm{C}_{\mathrm{a}}$ is the total curcumin concentration after standard addition; $\mathrm{C}_{\mathrm{t}}$ is the curcumin concentration in the test sample;

\section{Robustness}

Robustness was measured for curcumin standard solution $(5 \mu \mathrm{g} / \mathrm{mL})$ by different analysts and different instruments. The percentage relative standard deviation (\%RSD) values for different analysts (analyst 1 and 2) and different instruments (UV-Jasco V-630 and Secom am XTD6) were calculated.

\section{Estimation of curcumin in Live-well ${ }^{\mathrm{TM}}$, CUMIN capsule formulation \\ Preparation of Live-well ${ }^{\mathrm{TM}}$, CUMIN solution}

A stock solution $(100 \mu \mathrm{g} / \mathrm{mL})$ was prepared by dissolving $10 \mathrm{mg}$ of capsule powder of Live-well ${ }^{\mathrm{mx}}$, CUMIN in a $100 \mathrm{~mL}$ volumetric flask using ethyl acetate. The solution sonicated for $15 \mathrm{~min}$ and filtered through Whatman filter paper No. 41. From the clear stock solution, test solution was prepared at concentration $5 \mu \mathrm{g} / \mathrm{mL}$ by further dilution with ethyl acetate.

\section{Estimation of curcumin in Live-well ${ }^{\mathrm{TM}}$, CUMIN}

The percentage of curcumin present in the test solution $(5 \mu \mathrm{g} / \mathrm{mL})$ of marketed product Live-well ${ }^{\text {Th }}$ CUMIN capsule was estimated by using absorbance ratio method. Maximum absorbance was measured at 418 $\mathrm{nm}$ against ethyl acetate as blank.

\section{Statistical analysis}

Statistical analysis was carried out using Graph Pad Prism v 5.0. All the results were expressed as Mean \pm SD and \%RSD. ${ }^{22}$

\section{RESULTS}

\section{Method development}

Analytical method was developed and validated according to ICH Q2 (R1) guidelines Table 1.

\section{Method validation Specificity}

According to ICH Q2 (R1) guidelines, specificity is the ability to assess unequivocally the analyte in the presence of components which may be expected to be present. Results of specificity are shown in Figure 1.

\section{Linearity}

As per ICH Q2 (R1) guidelines, linearity of an analytical procedure is its ability (within a given range) to obtain test results which are directly proportional to the concentration (amount) of analyte in the sample. Results of linearity are shown in Table 2 and Figure 2. 


\section{Table 1: Summary of validation parameters of the proposed UV method}

\begin{tabular}{cc}
\hline Parameters & Results \\
\hline Absorption maximum $\left(\lambda_{\max }\right)$ & $418 \mathrm{~nm}$ \\
Beer's Law limit $(\mu \mathrm{g} / \mathrm{mL})$ & $1-5$ \\
Regression equation $(\mathrm{y}=\mathrm{mx}+\mathrm{c})$ & $\mathrm{y}=0.200 \mathrm{x}+0.065$ \\
Slope & 0.200 \\
Intercept & 0.065 \\
Coefficient of correlation & 0.999 \\
Repeatability (\% RSD), $(\mathrm{n}=6)$ & 0.946 \\
Accuracy (\% RSD) & $98.410-101.000$ \\
Precision (\% RSD) & Intra-day $=0.946$ \\
Robustness (\% RSD) & Inter-day $=0.869,0.750,0.777$ \\
\end{tabular}

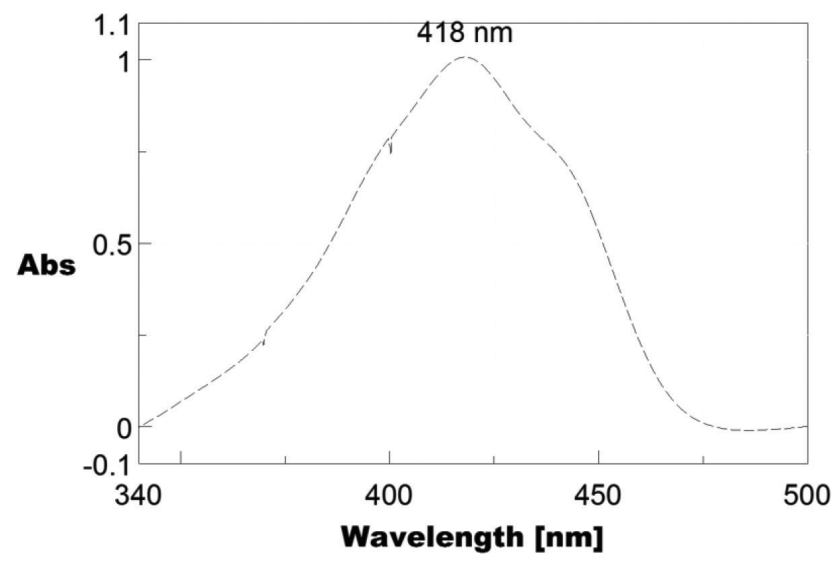

Figure 1: UV spectrum of curcumin in Ethylacetate.

\section{Range}

In accordance with ICH Q2 (R1) guidelines, range of an analytical procedure is the interval between the upper and lower concentration (amounts) of analyte in the sample (including these concentrations) for which it has been demonstrated that the analytical procedure has a suitable level of precision, accuracy and linearity. Results of range are shown in Table 2 and Figure 2.

\section{Precision}

Based on the ICH Q2 (R1) guidelines, precision of an analytical procedure expresses the closeness of agreement (degree of scatter) between a series of measurements obtained from multiple sampling of the same homogeneous sample under the prescribed conditions. Precision may be considered at three levels: repeatability, intermediate precision and reproducibility. Results of precision (repeatability and intermediate precision) are shown in Tables 3 and 4 .

\section{Accuracy}

Established ICH Q2 (R1) guidelines specified that the accuracy of an analytical procedure expresses the closeness of agreement between the value which is accepted either as a conventional true value or an accepted reference value and the value found. Results of accuracy are shown in Table 5.

\section{Robustness}

In agreement with ICH Q2 (R1) guidelines, the robustness of an analytical procedure is a measure of its capacity to remain unaffected by small, but

\begin{tabular}{ccc} 
Table 2: Linearity and range of the proposed UV method \\
\hline $\begin{array}{c}\text { Concentration of } \\
\text { curcumin }(\mu \mathrm{g} / \mathrm{mL})\end{array}$ & $\begin{array}{c}\text { Absorbance }\left(\boldsymbol{\lambda}_{\max }\right) \text { at } 418 \mathbf{~ n m} \\
(\text { Mean } \pm \text { SD) }(\mathbf{n}=3)\end{array}$ & \%RSD \\
\hline 1 & $0.2636 \pm 0.0011$ & 0.4172 \\
2 & $0.4724 \pm 0.0023$ & 0.4868 \\
3 & $0.6641 \pm 0.0082$ & 1.2347 \\
4 & $0.8742 \pm 0.0035$ & 0.4003 \\
5 & $1.0671 \pm 0.0014$ & 0.1311 \\
\hline
\end{tabular}

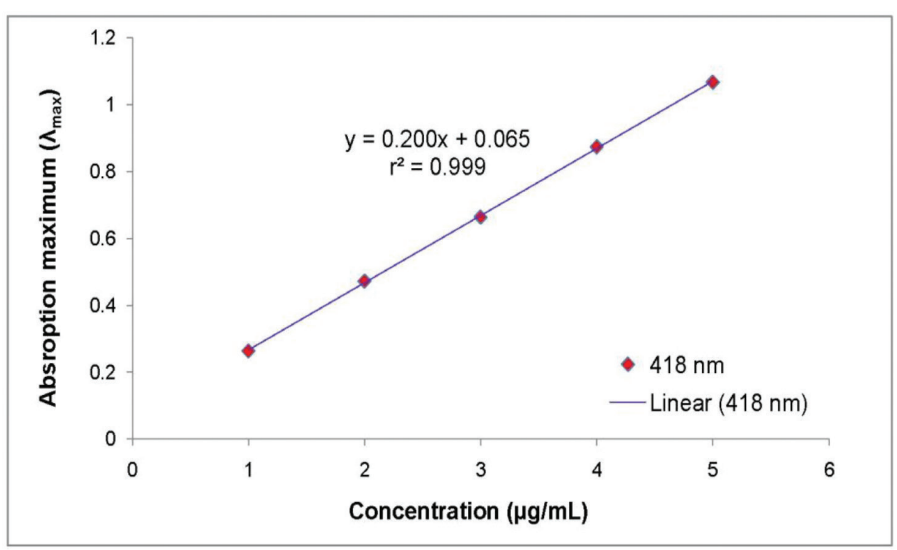

Figure 2: Linearity and range of the proposed UV method.

deliberate variations in method parameters and provides an indication of its reliability during normal usage. Results of robustness are shown in Table 6.

\section{Estimation of curcumin in polyherbal formulation (Live- well ${ }^{\mathrm{TM}}$, CUMIN)}

Results of assay of curcumin in polyherbal formulation (Live-well ${ }^{\mathrm{Tx}}$, CUMIN) capsule formulation is shown in Table 7.

\section{DISCUSSION}

\section{Method development}

During method development phase, the use of a few milliliters of ethyl acetate as solvent resulted in considerable outcome in UV analysis. Hence, the solvent was optimized to ethyl acetate. The main reason for the selection of ethyl acetate as solvent for developing UV method was based on its biodegradable and ecofriendly (not dangerous for the environment) properties. It is one of the most commonly used solvent in chromatographic separation of curcuminoids. Furthermore, ethyl acetate absorbs in the wavelength range of 200 to $235 \mathrm{~nm}$ that does not interfere with the absorption range of curcuminoids at 400-600 nm. The proposed UV-spectrophotometric method was found to be specific and selective for assay of curcumin in polyherbal formulations, the optimized solvent was ethyl acetate and wavelength of maximum absorption $\left(\lambda_{\max }\right)$ of curcumin was appeared at $418 \mathrm{~nm}$ Figure 1. 
Table 4: Intermediate precision (Inter-day precision) of the proposed UV method

\begin{tabular}{ccc}
\hline \multicolumn{3}{c}{ Intermediate precision (Inter-day precision) $(\mathrm{n}=3)$} \\
\hline Curcumin $(\mu \mathrm{g} / \mathrm{mL})$ & $\begin{array}{c}\text { Absorbance at 418 } \mathrm{nm} \\
\text { (Mean } \pm \text { SD) }\end{array}$ & \%RSD \\
\hline 1 & $0.2643 \pm 0.0023$ & 0.8693 \\
3 & $0.6544 \pm 0.0049$ & 0.7500 \\
5 & $1.0583 \pm 0.0082$ & 0.7770 \\
\hline
\end{tabular}

Table 3: Repeatability (Intra-day precision) of the proposed UV method.

\begin{tabular}{ccc}
\hline \multicolumn{3}{|c}{ Repeatability (Intra-day precision) $(\mathbf{n}=6)$} \\
\hline Curcumin $(\mu \mathrm{g} / \mathrm{mL})$ & $\begin{array}{c}\text { Absorbance at } \mathbf{4 1 8} \mathbf{~ n m} \\
\text { (Mean } \pm \text { SD) }\end{array}$ & \%RSD \\
\hline 1 & $0.2645 \pm 0.0025$ & 0.9462 \\
\hline
\end{tabular}

\section{Table 5: Accuracy studies of the proposed UV method}

\begin{tabular}{ccccccc}
\hline $\begin{array}{c}\text { Initial amount of } \\
\text { curcumin }(\mu \mathrm{g} / \mathrm{mL})\end{array}$ & $\begin{array}{c}\text { Added amount of } \\
\text { curcumin }(\mu \mathrm{g} / \mathrm{mL})\end{array}$ & $\begin{array}{c}\text { Predicted concentration } \\
(\mu \mathrm{g} / \mathrm{mL})\end{array}$ & $\begin{array}{c}\text { Observed concentration } \\
(\mu \mathrm{g} / \mathrm{mL})\end{array}$ & $\begin{array}{c}\text { Residual concentration } \\
(\mu \mathrm{g} / \mathrm{mL})\end{array}$ & $\begin{array}{c}\% \text { Mean } \\
\text { Recovery }\end{array}$ & $\begin{array}{c}\% \mathrm{RSD} \\
0\end{array}$ \\
\hline 2 & $1(50 \%)$ & 3 & 2.9875 & 0.0125 & 99.5833 \\
2 & $2(100 \%)$ & 4 & 4.0400 & -0.0400 & 1.0956 \\
2 & $3(150 \%)$ & 5 & 4.9205 & 0.0795 & 0.7801 \\
\hline
\end{tabular}

Table 6: Robustness of the proposed UV method

\begin{tabular}{cccc}
\hline Variable parameters & $\begin{array}{c}\text { Absorbance at 418 } \mathrm{nm} \\
\text { (Mean } \pm \text { SD) }\end{array}$ & \%RSD & Mean \% recovery \\
\hline Analyst 1 & $0.2626 \pm 0.0015$ & 0.5816 & 101.27 \\
Analyst 2 & $0.2635 \pm 0.0015$ & 0.5915 & 99.79 \\
Instrument 1 (Jasco V-630) & $0.2599 \pm 0.0011$ & 0.4237 & 99.81 \\
Instrument 2 (Secomam & $0.2610 \pm 0.0025$ & 0.9639 & 100.13 \\
XTD6) & & & \\
\hline
\end{tabular}

Table 7: Assay results for curcumin estimation in Live-well ${ }^{\mathrm{Tm}}$, CUMIN capsule formulation

\begin{tabular}{|c|c|c|c|c|c|}
\hline Formulation & $\begin{array}{c}\text { Amount of formulation } \\
\text { tested }\end{array}$ & $\begin{array}{l}\text { Absorbance at } 418 \mathrm{~nm} \\
(\text { Mean } \pm \text { SD) }(n=3)\end{array}$ & $\%$ RSD & $\begin{array}{l}\text { Amount of curcumin } \\
\text { found }(n=3)\end{array}$ & $\begin{array}{c}\text { Mean } \% \text { recovery of } \\
\text { curcumin }^{\text {a }}\end{array}$ \\
\hline $\begin{array}{c}\text { Live-well }{ }^{\text {mox}}, \text { CUMIN } \\
\text { Capsule }\end{array}$ & $5 \mu \mathrm{g} / \mathrm{mL}$ & $0.8255 \pm 0.0022$ & $0.2755 \%$ & $3.8028 \mu \mathrm{g} / \mathrm{mL}$ & 76.0560 \\
\hline
\end{tabular}

${ }^{\text {a }}$ Label claim is total percentage of curcuminoids minimum 95\%

\section{Method validation}

The method was validated according to ICH guidelines ${ }^{23,24}$ Table 1 . Specificity was confirmed by comparing the UV-scans obtained from the curcumin standard concentrations $(1-5 \mu \mathrm{g} / \mathrm{mL})$, all runs exhibited a prominent peak at $418 \mathrm{~nm}$ and it was confirmed as average wavelength of maximum absorbance $\left(\lambda_{\max }\right)$. Therefore, it was selected for linearity studies Table 2. The regression plots showed compliance with Beer Lambert's law in the concentration range of $1-5 \mu \mathrm{g} / \mathrm{mL}$ with a correlation coefficient $(\mathrm{r})$ of 0.999 indicate a good linearity between absorbance and concentration Figure 2. Range (working range) was confirmed by the results where UV absorbance was directly proportional to the true concentration of the analyte was predefined by the method of goodness-of-fit test at $418 \mathrm{~nm}$ Figure 2. The range of analyte concentrations that the proposed method can directly measure was $(1-5 \mu \mathrm{g} / \mathrm{mL})$ and it was confirmed by accuracy studies as 50 to $150 \%$ of the test concentration. The analyte concentration was in the measurable range of the instrument. The repeatability (\%RSD) and intermediate precision (\%RSD) were observed for analysis of three independent triplicate samples. The repeatability \%RSD value was found to be $0.9462 \%$ in ethyl acetate Table 3 and the intermediate precision \%RSD values for selected samples in three consecutive different days were found to be $0.8693,0.7500$ and $0.7770 \%$ in ethyl acetate Table 4, respectively. The low values of \%RSD in both intra-day and an inter-day analysis was found to be less than $<2 \%$. Hence, the precision was confirmed. The accuracy of the proposed method was established by standard addition method Table 5 , estimated by analyzing samples spiked at three different concentrations (low, medium, high) covering the working range $(1-5 \mu \mathrm{g} / \mathrm{mL})$. The data revealed the closeness of the observed value to the true value for the sample. Accuracy was assessed as the \% recovery of the added curcumin concentrations. Recovery values for the standard addition method followed for the curcumin analysis ranged from 98.4100 to $101.000 \%$ ensure an accurate method as well as non-interference with the excipient of formulation Table 5. The method was found to be robust as indicated by reliable and consistent absorbance with changes made with respect to the analyst (analyst 1 and 2) and instrument (UV-Jasco V-630 and UV-Secom am XTD6), triplicate determination at selected concentration $(1 \mu \mathrm{g} / \mathrm{mL})$ of the curcumin was carried out and the \%RSD values in both the parameters were appeared to be $<2 \%$ and the percentage recovery was appeared in the range 99.79 to $101.27 \%$ Table 6 . Hence robustness was established

\section{Estimation of curcumin in polyherbal formulation (Live- well $^{\mathrm{TM}}$, CUMIN)}

The method was successfully employed for the estimation of curcumin in Live-well ${ }^{\mathrm{Tw}}$, CUMIN capsule formulation and the percentage curcumin was determined and it was found to be $76.0560 \%$ with \%RSD value $0.2755 \%$ Table 7 . The percentage curcumin estimated by the proposed method 
was in good agreement with natural composition ratio of curcumin found in turmeric extracts ${ }^{25}$ (curcumin 76\%, demethoxycurcumin 19\% and bisdemethoxycurcumin 5\%) used in clinical trials. ${ }^{26-28}$

\section{CONCLUSION}

In conclusion, we have developed and validated a method that was found to be eco-friendly, simple, cost-effective and was successfully applied for the estimation of curcumin in Live-well ${ }^{\text {sa }}$, CUMIN capsules without involvement of any interference from other phytochemicals forming part of the formulation ingredients. Based on the results and statistical parameters demonstrate that this method could be the specific and remarkable for the analysis of curcumin in polyherbal formulations or turmeric extracts.

\section{ACKNOWLEDGEMENT}

One of the authors (Ashwinder Singh A/L Guru dev Singh) is thankful to the Dean, Faculty of Pharmacy and to the Vice-chancellor, Asia Metropolitan University, Malaysia for providing Bachelor of Pharmacy (Hons) Graduate Research Grant, instrumentation facilities to carry out the research work.

\section{CONFLICTS OF INTEREST}

None

\section{REFERENCES}

1. Hills P. J Pharm Med Res. 2016;2(1):39-4

2. Guo L, Duan L, Dou LL, Liu LL, Yang H, Liu EH, et al. Quality standardization of herbal medicines using effective compounds combination as labeled constituents. J Pharm Biomed Anal. 2016;129:320-31.

3. Duraiswamy A, Shanmugasundaram D, Sheela C. Evaluation of the phytochemical constituents in ADJ6, an anti-diabetic polyherbal formulation by GC-MS. Journal of Pharmacognosy and Phytochemistry. 2016;5(1):173-1.

4. Hwang KW, Son D, Jo HW, Kim CH, Seong KC, Moon JK. Levels of curcuminoid and essential oil compositions in turmeric's (Curcuma longa L.) grown in Korea. Applied Biological Chem. 2016;59(2):209-15

5. Kaur P. Comparative Study of Pharmacognostical and Preliminary Phytochemical Investigation of Curcuma Longa Leaves and Rhizomes. Imperial Journal of Interdisciplinary Research. 2016;2(7)

6. Mehanny M, Hathout RM, Geneidi AS, Mansour S. Bisdemethoxycurcumin loaded polymeric mixed micelles as potential anti-cancer remedy: Preparation optimization and cytotoxic evaluation in a HepG-2 cell model. J Molecular Liq. 2016;214:162-70.

7. Yue GG, Jiang L, Kwok HF, Lee JK, Chan KM, Fung KP, et al. Turmeric ethanolic extract possesses stronger inhibitory activities on colon tumour growth than curcumin-The importance of turmerones. J Functional Foods. 2016;22:565-77.

8. Rao PJ, Khanum H. A green chemistry approach for nanoencapsulation of bioactive compound-Curcumin. LWT-Food Sci Technol. 2016;65:695-702.

9. Chadwick BJ. 4 Technology Change-Enabling Clinical Research and Drug Development Processes. New Drug Approval Process. 2016,19:29.

10. Chainani-Wu N. Safety and anti-inflammatory activity of curcumin: a compo- nent of turmeric (Curcuma longa). J Alterna Complement Med. 2003;9(1):161-8.

11. Hu XQ, Sun Y, Lau E, Zhao M, Su SB. Advances in Synergistic Combinations of Chinese Herbal Medicine for the Treatment of Cancer. Current Cancer Drug Tar. 2016;16(4):346-56.

12. Azmi NS, Bhat R, Yeoh TK. Quality evaluation of novel cookies prepared by supplementing with fresh turmeric flower (Curcuma longa L.) extracts as a value added functional ingredient. Inter Food Res J. 2016;23(4).

13. Kadam PV, Bhingare CL, Nikam RY, Pawar SA. Development and validation of UV Spectrophotometric method for the estimation of Curcumin in cream formulation. Pharm Methods. 2013;30;4(2):43-5.

14. Syed HK, Liew KB, Loh GO, Peh KK. Stability indicating HPLC-UV method for detection of curcumin in Curcuma longa extract and emulsion formulation. Food Chem. 2015;170:321-6.

15. Zhou Y, Wang S, Ding T, Wu M, Geng P, Zhang Q, Ma J. Pharmacokinetic interaction study of combining imatinib with dasatinib in rats by UPLC-MS/MS. Drug Dev Indus Pharm. 2015;41(12):1948-53.

16. Taha MN, Krawinkel MB, Morlock GE. High-performance thin-layer chromatography linked with (bio) assays and mass spectrometry-a suited method for discovery and quantification of bioactive components? Exemplarily shown for turmeric and milk thistle extracts. J Chromatography A. 2015;1394:137-47.

17. Mangolim CS, Moriwaki C, Nogueira AC, Sato F, Baesso ML, Neto AM, et al. Curcumin- $\beta$-cyclodextrin inclusion complex: Stability, solubility, characterization by FT-IR, FT-Raman, X-ray diffraction and photoacoustic spectroscopy, and food application. Food Chem. 2014;153:361-70.

18. Ashraf K, Mujeeb M, Ahmad A, Ahmad N, Amir M. Determination of Curcuminoids in Curcuma longa Linn. by UPLC/Q-TOF-MS: An Application in Turmeric Cultivation. J Chromatography Sci. 2015;53(8):1346-52.

19. Shen $Y$, Han $C$, Chen $X$, Hou $X$, Long Z. Simultaneous determination of three Curcuminoids in Curcuma wenyujin $\mathrm{YH}$ chen et $\mathrm{C}$. Ling. by liquid chromatographytandem mass spectrometry combined with pressurized liquid extraction. J Pharm Biomed Anal. 2013;81:146-50.

20. Gowthamarajan K, Jawahar N, Wake P, Jain K, Sood S. Development of buccal tablets for curcumin using Anacardium occidentale gum. Carbohydrate. Polymers. 2012;88(4):1177-83.

21. Guideline $\mathrm{IH}$. Validation of analytical procedures: text and methodology. Q2 (R1). 2005.

22. Motulsky H. Analyzing data with Graph Pad prism. Graph Pad Software Incorporated. 1999

23. Sonawane SD, Nirmal SA, Patil AN, Pattan SR. Development and validation of HPTLC method to detect curcumin and gallic acid in polyherbal formulation. J Liquid Chromatography Related Technol. 2011;34(20):2664-73.

24. Mohanty C, Sahoo SK. The in vitro stability and in vivo pharmacokinetics of curcumin prepared as an aqueous nanoparticulate formulation. Biomaterials. 2010;31(25):6597-611.

25. Jayaprakasha GK, Rao LJ, Sakariah KK. Antioxidant activities of curcumin demethoxycurcumin and bisdemethoxycurcumin. Food Chem. 2006;98(4):720-4.

26. Gowda NK, Ledoux DR, Rottinghaus GE, Bermudez AJ, Chen YC. Efficacy of turmeric (Curcuma longa), containing a known level of curcumin, and a hydrated sodium calcium aluminosilicate to ameliorate the adverse effects of aflatoxin in broiler chicks. Poultry Sci. 2008;87(6):1125-30.

27. Wichitnithad W, Jongaroonngamsang N, Pummangura S, Rojsitthisak P. A simple isocratic HPLC method for the simultaneous determination of curcuminoids in commercial turmeric extracts. Phytochemical. Anal. 2009;20(4):314-9.

28. Schiborr C, Eckert GP, Rimbach G, Frank J. A validated method for the quantification of curcumin in plasma and brain tissue by fast narrow-bore high-performance liquid chromatography with fluorescence detection. Anal. Bioanalytical. Chem. 2010;397(5):1917-25.

Article History: Submission Date : 05-04-2017 ; Revised Date : 18-06-2017; Acceptance Date : 31-07-2017.

Cite this article: Singh A, Avupati VR. Development and Validation of UV-Spectrophotometric method for the Estimation of Curcumin in Standardised Polyherbal Formulations. J Young Pharm. 2017;9(4):491-5. 